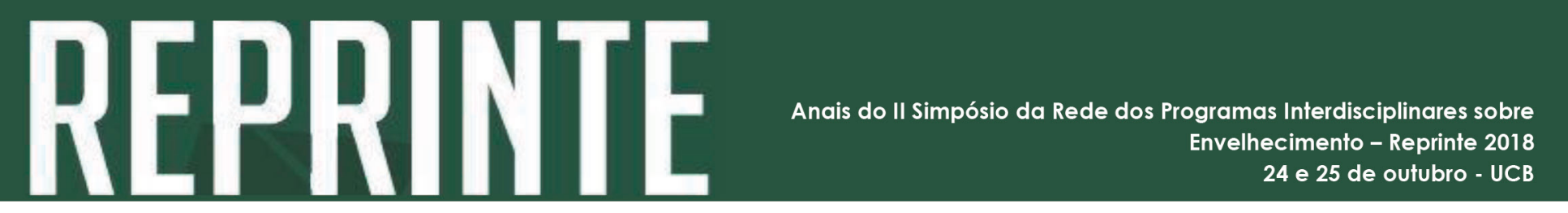

http://dx.doi.org/10.5335/rbceh.v16i1.9862

\title{
23) Percepções de moradores idosos da Mooca (São Paulo) com relação ás novas tecnologias para comunicação e informação
}

Lilian Ourém Batista Vieira Cliquet ${ }^{1}$; Maria Luiza Betestti²; Bibiana Graeff ${ }^{2}$

\section{Resumo}

O desenvolvimento tecnológico como envelhecimento tem atingido cada vez mais indivíduos em países desenvolvidos e em desenvolvimento. O aumento de usuários de dispositivos móveis, computadores, e aplicativos por pessoas com mais de 60 anos tem anunciado a transformação da comunicação e informação para essa geração.

Palavras chave: Tecnologia; Cidade Amiga do Idoso; Informação; Comunicação; Envelhecimento.

\section{Objetivo}

Observar a percepção, dos idosos, moradores da Mooca que participaram da Pesquisa Bairro amigo do Idoso, em relação às novas tecnologias.

\section{Métodos}

Foram analisados 3 grupos focais dessa pesquisa envolvendo 14 participantes, $57,15 \%$ do sexo feminino e 42,85\% do sexo masculino com idades de 60 anos ou mais. Análise de conteúdo, englobou as fases: pré-análise, exploração do material e tratamento dos resultados.

1 Mestranda no curso de Gerontologia. Escola de Artes, Ciências e Humanidades, Universidade de São Paulo. Endereço para correspondência: R. Arlindo Béttio, 1000, Ermelino Matarazzo São Paulo - SP, Brasil. CEP: 03828-000. Email: lilian.cliquet@usp.br

2 Professoras no curso de Gerontologia na Escola de Artes, Ciências e Humanidade da Universidade de São Paulo. E-mails (na ordem em que aparecem): maria.luisa@usp.br; bibiana.graeff@usp.br 


\section{Resultados}

Através dos dados coletados nos grupos focais, foi possível observar que a tecnologia está de alguma forma inserida no cotidiano das pessoas, não necessariamente sendo utilizadas por elas, mas permeando seu dia, das próprias observações e análises no contexto social.

\section{Conclusão}

Apesar da corrida tecnológica, ela não parece ser acompanhada de maneira tão entusiasmada por essa população. A necessidade do uso de celular e internet ou redes sociais não se manifestou como essencial para eles, sendo mais utilizada pelos idosos mais jovens.

\section{Perceptions of elderly residents of Mooca (São Paulo) in relation to new technologies for communication and information}

\section{Abstract}

Technological development such as aging has been reaching more and more individuals in developed and developing countries. The increase in mobile users, computers, and applications by people over 60 has announced the transformation of communication and information for this generation.

Keywords: Technology; Friendly City of the Elderly; Information; Communication; Aging. 